\title{
A versatile and an efficient synthesis of 5-substituted-1H-tetrazoles
}

\author{
MADHUSUDANA REDDY MUTHUKUR BHOJE GOWD \\ and MOHAMED AFZAL PASHA* \\ Department of Studies in Chemistry, Central College Campus, Bangalore University, \\ Bangalore 560 001, India \\ e-mail: m_af_pasha@ymail.com
}

MS received 17 June 2010; revised 2 November 2010; accepted 4 November 2010

\begin{abstract}
A simple, efficient and a versatile method for the synthesis of 5 -substituted-1H-tetrazoles by a $[3+2]$-cycloaddition reaction of arylnitriles with sodium azide in DMF using $\mathrm{ZrOCl}_{2} \cdot 8 \mathrm{H}_{2} \mathrm{O}$ as catalyst has been developed. The reactions work well at $100^{\circ} \mathrm{C}$ and give the desired products in excellent yield. The examples studied include arylnitriles having electron donating as well as electron releasing groups on the arene nucleus.
\end{abstract}

Keywords. Tetrazoles; $\mathrm{ZrOCl}_{2} \cdot 8 \mathrm{H}_{2} \mathrm{O}$; DMF; arylnitriles; sodium azide.

\section{Introduction}

Tetrazoles are a class of heterocycles that have received attention due to their wide range of applications. ${ }^{1}$ In general, this nitrogen-rich ring system is used in propellants, ${ }^{2}$ explosives, ${ }^{3}$ and in pharmaceuticals. ${ }^{4}$ In addition, tetrazoles are important synthons in synthetic organic chemistry, ${ }^{5}$ and also used as precursors of carbenes in flash vacuum pyrolysis. ${ }^{6}$ Various tetrazole-based compounds have also shown good coordination properties and are able to form stable complexes with several metal ions. ${ }^{7}$ Furthermore, the tetrazole ring has strong electronwithdrawing property and tetrazolyl halides have been successfully used in organic synthesis as derivatising agents for the chemical modification of alcohols. ${ }^{8}$

One of the well-known methods of synthesis of 5substituted- $1 H$-tetrazoles is by a [3+2]-cycloaddition between hydrazoic acid and cyanides. ${ }^{9}$ While hydrazoic acid is highly poisonous, explosive and low boiling liquid $\left(\sim 37^{\circ} \mathrm{C}\right)$; trialkyltin azide (used in the synthesis of tetrazoles) is also volatile and toxic reagent, and is not readily available. ${ }^{10}$ Recently, methods using trimethylsilyl azide (TMS-N ${ }_{3}$ ) are reported by Yamamoto et al., for the synthesis of 5substituted-tetrazoles; ${ }^{11 \mathrm{a}}$ and 2-allylated-5-substituted-

\footnotetext{
$\overline{\text { *For correspondence }}$
}

tetrazoles. ${ }^{11 \mathrm{~b}, \mathrm{c}}$ Trimethylsilyl azide is also volatile and toxic reagent. More recently, $\mathrm{CuO},{ }^{11 \mathrm{~d}}$ triethylammonium chloride in nitrobenzene, ${ }^{11 \mathrm{e}} \mathrm{ZnCl}_{2}$ and Tungstates ${ }^{11 \mathrm{f}}$ have been reported for the promotion of this reaction.

In order to overcome the limitations, syntheses have been designed either to control the hydrazoic acid formation ${ }^{12}$ or to use a large excess of azide ions in the presence of metal catalysts ${ }^{13}$ or strong Lewis acids. ${ }^{14}$ Overall, these procedures are less desirable due to the disadvantages of long reaction durations, low yield of products. The use of sodium azide as substrate in place of the hydrazoic acid or $\mathrm{TMS}^{-\mathrm{N}_{3}}$ would be practically convenient. Zirconium compounds on the other hand, are reported as excellent catalysts for various organic reactions. ${ }^{15}$ Among the various zirconium compounds, zirconyl chloride is most effective, relatively non-toxic, ${ }^{16}$ inexpensive and non-sensitive to air. A wide range of applications of zirconyl chloride as a catalyst in organic synthesis are reported. Some of them include oxidation, ${ }^{17 a}$ acylation, ${ }^{17 \mathrm{~b}}$ esterification, ${ }^{17 \mathrm{c}-\mathrm{e}}$ nitration, ${ }^{17 \mathrm{f}}$ Michael addition, ${ }^{17 \mathrm{~g}}$ Mannich-type reactions, ${ }^{17 \mathrm{~h}}$ Biginelli reaction, ${ }^{17 \mathrm{i}}$ synthesis of 2-aliphatic aryloxazolines, ${ }^{17 j}$ synthesis of benzimidazoles, ${ }^{17 \mathrm{k}}$ synthesis of benzothiazoles, ${ }^{171}$ and synthesis of bis-oxazolines. ${ }^{17 \mathrm{~m}}$ Recently, zirconyl chloride has been proved to be highly effective catalyst for the synthesis of $\beta$-acetamido ketones, ${ }^{18 a}$ enaminones and enamino esters, ${ }^{18 \mathrm{~b}} \alpha$-aminophospho- 
nates, ${ }^{18 \mathrm{c}}$ homoallylic alcohols or amines ${ }^{18 \mathrm{~d}}$ and 1,8-dioxo-octahydroxanthenes. ${ }^{18 \mathrm{e}}$

In continuation of our work on the synthesis of biologically important compounds using simple, efficient, non-toxic and readily available catalysts, ${ }^{19}$ we report herein the synthesis of 5 -substituted- $1 H$-tetrazoles by a [3+2]-cycloaddition reaction of arylnitriles with sodium azide in DMF using $\mathrm{ZrOCl}_{2} \cdot 8 \mathrm{H}_{2} \mathrm{O}$ as a catalyst (scheme 1).

\section{Experimental}

\subsection{Materials}

All solvents and reagents were commercial and used without further purification unless otherwise stated. Nitrile (1h, table 1) was prepared from corresponding aldehyde as reported in the literature. ${ }^{20}$

\subsection{Apparatus}

Melting points were determined on a Raaga, Chennai, India melting point apparatus. Nuclear magnetic resonance spectra were obtained on a Bruker AMX spectrophotometer in DMSO- $d_{6}$ at $400 \mathrm{MHz}$ instrument. Chemical shifts are obtained in parts per million $(\delta)$ and are measured using tetramethylsilane (TMS) as reference. GC-MS spectra were obtained on a Shimadzu GC-MS QP 5050A (equipped with a 30 meter length and $0.32 \mathrm{~mm}$ of diameter BP-5 column with the column temperature $80-15-250^{\circ} \mathrm{C}$ ). IR spectra were recorded on a Shimadzu FT-IR-8400s Spectrophotometer using $\mathrm{KBr}$ pellets and are reported as wave numbers $\left(\nu \mathrm{cm}^{-1}\right)$.

\subsection{General procedure for preparation of 5-(4'-methoxyphenyl)tetrazole (2e)}

$\mathrm{ZrOCl}_{2} \cdot 8 \mathrm{H}_{2} \mathrm{O}(10 \mathrm{~mol} \%)$ is added to a mixture of 4 methoxybenzonitrile $(0 \cdot 266 \mathrm{~g}, 2 \mathrm{mmol})$, sodium azide $(0 \cdot 195 \mathrm{~g}, 3 \mathrm{mmol})$ in DMF $(5 \mathrm{~mL})$ and stirred at $100^{\circ} \mathrm{C}$ for $6 \mathrm{~h}$. After completion of the reaction (TLC), the catalyst was separated by filtration, washed with ethyl acetate and the filtrate was taken into ethyl acetate $(30 \mathrm{~mL})$ and $5 \mathrm{~N} \mathrm{HCl}(20 \mathrm{~mL})$ was then added and stirred vigorously. The organic layer was separated, and the aqueous layer was washed with ethyl acetate $(20 \mathrm{~mL})$, and the combined extract was washed with water, dried over anhydrous $\mathrm{Na}_{2} \mathrm{SO}_{4}$ and concentrated to get the crude crystalline 5-(4'-methoxyphenyl)- $1 \mathrm{H}$ tetrazole. Column chromatography was performed using silica gel (100-200 mesh) to afford pure product as white solid $(0 \cdot 316 \mathrm{~g}, 90 \%), \mathrm{mp}=230-232^{\circ} \mathrm{C}$. IR $\left(\mathrm{KBr}, \nu \mathrm{cm}^{-1}\right.$ ) 3200-3300 (br), 1298, 1184, 1035, 750; ${ }^{1} \mathrm{H}$ NMR $\left(400 \mathrm{MHz}\right.$, DMSO- $\left.d_{6}\right): \delta 3 \cdot 82(3 \mathrm{H}, \mathrm{s}), 7 \cdot 13$ $(2 \mathrm{H}, \mathrm{d}, J=9.0 \mathrm{~Hz}), 7.95(2 \mathrm{H}, \mathrm{d}, J=9.0 \mathrm{~Hz}) ; \mathrm{GC}-$ MS: m/z 175·1.

\section{Results and discussion}

In search of an effective catalyst and to optimize the experimental conditions, the reaction of 4methoxybenzonitrile and sodium azide was considered as the model reaction, and various zirconium compounds were tested as catalysts. The best results were obtained by using $10 \mathrm{~mol} \%$ of $\mathrm{ZrOCl}_{2} \cdot 8 \mathrm{H}_{2} \mathrm{O}$ (table 2, entry e) in DMF as a solvent at $100^{\circ} \mathrm{C}$ after 6 $\mathrm{h}$ to get the respective product in $90 \%$ yield. Under similar conditions, other zirconium compounds such as $\mathrm{ZrO}_{2}, \mathrm{ZrCl}_{4}$ and $\mathrm{ZrO}\left(\mathrm{ClO}_{4}\right)_{2} \cdot 6 \mathrm{H}_{2} \mathrm{O}$ gave lower yields of tetrazole even after $10 \mathrm{~h}$ (table 2, entries ac). Other metal catalysts such as $\mathrm{CuCl}_{2}, \mathrm{FeCl}_{3}, \mathrm{NiCl}_{2}$ or $\mathrm{CoCl}_{2}$ were also less effective in the promotion of this reaction (table 2, entries $\mathbf{f}-\mathbf{i}$ ). The effect of solvent on the formation of tetrazoles was also studied. Use of other solvents (other than DMF) such as $\mathrm{DCM}, \mathrm{MeCN}$ and $\mathrm{MeOH}$ at reflux required longer time $(20 \mathrm{~h})$ to give the desired product in $30 \%, 61 \%$ and $45 \%$ yield respectively. The necessity to use the catalyst was realized by the observation that no product was detected when the reaction was carried out in the absence of any catalyst either at room temperature or at $100^{\circ} \mathrm{C}$ under neat conditions (table 2, entry d).

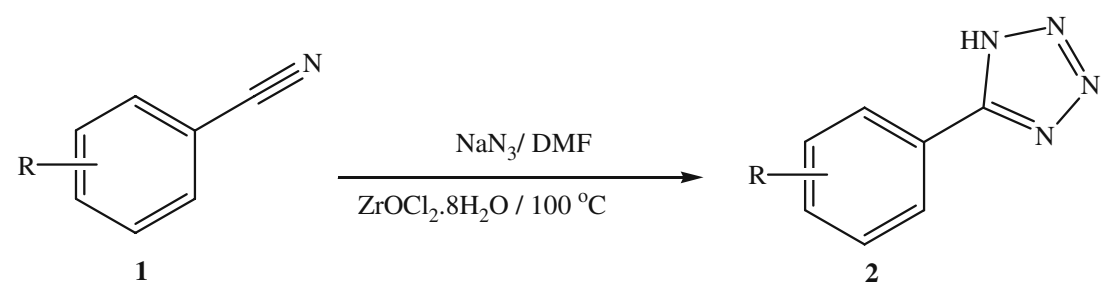

Scheme 1. Synthesis of $1 H$-tetrazoles from nitriles and catalytic $\mathrm{ZrOCl}_{2} \cdot 8 \mathrm{H}_{2} \mathrm{O}$. 
Table 1. Synthesis of tetrazoles from aromatic nitriles with sodium azide.

\begin{tabular}{|c|c|c|c|c|}
\hline Entry & Nitrile(1) & Tetrazole $(\mathbf{2})^{a}$ & Time(h) & Yield $(\%)^{b}$ \\
\hline $\mathbf{a}$ & & & 6 & 95 \\
\hline $\mathbf{b}$ & & & $6 \cdot 5$ & 93 \\
\hline c & & & 6 & 90 \\
\hline d & & & 6 & 88 \\
\hline e & & & 6 & 90 \\
\hline $\mathbf{f}$ & & & 5 & 88 \\
\hline g & & & $5 \cdot 5$ & 92 \\
\hline $\mathbf{h}$ & & & 5 & 91 \\
\hline $\mathbf{i}$ & & & 5 & 93 \\
\hline $\mathbf{j}$ & & & 9 & 87 \\
\hline
\end{tabular}

${ }^{a}$ All reactions were performed using a nitrile $(2 \mathrm{mmol})$, sodium azide $(3 \mathrm{mmol})$ and $\mathrm{ZrOCl}_{2} \cdot 8 \mathrm{H}_{2} \mathrm{O}(10 \mathrm{~mol} \%)$.

${ }^{b}$ Isolated yield; and All the compounds are known and physical properties agree with literature values [refs. 9-11]. 
Table 2. Effect of catalyst on the formation of 5-(4'methoxyphenyl)-1 $H$-tetrazole.

\begin{tabular}{|c|c|c|c|}
\hline Entry & Catalyst $^{a}$ & $\begin{array}{l}\text { Time }(\mathrm{h}) / \text { Temp } \\
\left({ }^{\circ} \mathrm{C}\right)\end{array}$ & $\begin{array}{l}\text { Yield, 2e } \\
(\%)^{b}\end{array}$ \\
\hline $\mathbf{a}$ & $\mathrm{ZrO}_{2}$ & $10 / 100$ & 43 \\
\hline b & $\mathrm{ZrCl}_{4}$ & $10 / 100$ & 52 \\
\hline c & $\begin{array}{l}\mathrm{ZrO} \\
\left(\mathrm{ClO}_{4}\right)_{2} \cdot 6 \mathrm{H}_{2} \mathrm{O}\end{array}$ & $10 / 100$ & 63 \\
\hline d & No Catalyst & $20 / \mathrm{rt}$ & $\begin{array}{l}\text { no product/ } \\
(10)^{c}\end{array}$ \\
\hline e & $\mathrm{ZrOCl}_{2} \cdot 8 \mathrm{H}_{2} \mathrm{O}$ & $6 / 100$ & 90 \\
\hline f & $\mathrm{CuCl}_{2}$ & $10 / 100$ & 58 \\
\hline g & $\mathrm{FeCl}_{3}$ & $10 / 100$ & 66 \\
\hline h & $\mathrm{NiCl}_{2}$ & $10 / 100$ & 59 \\
\hline i & $\mathrm{CoCl}_{2}$ & $10 / 100$ & 44 \\
\hline
\end{tabular}

${ }^{a}$ All reactions were performed using an 4-methoxybenzonitrile ( $2 \mathrm{mmol})$, sodium azide $(3 \mathrm{mmol})$ and $10 \mathrm{~mol} \%$ of catalyst in DMF $(5 \mathrm{ml})$

${ }^{b}$ yields are based on GC-MS analysis

${ }^{c}$ Reaction at $100^{\circ} \mathrm{C}$ without solvent and catalyst

To establish generality, the catalyst has been applied successfully for various arylnitriles with sodium azide and the results are presented in table 1. From table 1 it is clear that, excellent results were obtained with aryl, heteroaryl, arylmethyl nitriles. It can also be seen from this Table that, the reaction is compatible with various functional groups such as $-\mathrm{Cl},-\mathrm{OCH}_{3},-\mathrm{NO}_{2}$ and $-\mathrm{OH}$ that do not interfere with the catalyst. However, benzylnitrile required longer reaction time when compared to other aldehydes (table 1 , entry $\mathbf{2 j}$ ).

\section{Conclusion}

We have reported an efficient method of the synthesis of 5-substituted- $1 H$-tetrazoles from various nitriles with sodium azide in the presence of catalytic amount of $\mathrm{ZrOCl}_{2} \cdot 8 \mathrm{H}_{2} \mathrm{O}$. This method is applicable to a range of nitriles including aromatic, arylmethyl and heterocyclic nitriles. It has also been shown that, the yields are high and reactions completion time is within 5-9 h. The catalyst used is readily available and is environment friendly.

\section{Acknowledgement}

One of the authors M S Reddy wishes to thank Mr. M B Narayana Reddy, Mathematics Teacher, Govt. School, Hemavathi, Madakasira Taluk, Andra Pradesh, India, for the constant encouragement.

\section{References}

1. (a) Singh H, Chawla A S, Kapoor V K, Paul D and Malhotra R K 1980 Prog. Med. Chem. 17 151; (b) Genin M J, Allwine D A, Anderson D J, Barbachyn M R, Emmert D E, Garmon S A, Graber D R, Grega K C, Hester J S, Hutchinson D K, Morris J, Reischer R J, Ford C W, Zurenko G E, Hamel J C, Schaadt R D, Stapert D and Yagi B H 2000 J. Med. Chem. 43 953, and references cited therein; (c) Butler R N, 1996 Comprehensive Heterocyclic Chemistry (eds) A R Katritzky, C W Rees and E F V Scriven (U K: Pergamon-Oxford) Vol 4

2. Brown M, US Patent 3, 1967, 338, 915. Chem. Abstr. 1968, 87299

3. Tarver C M, Goodale T C, Shaw R and Cowperthwaite M, Off Nav. Res. (Tech Rep) ACR (US), ACR-221, Proc. Symp. Int. Detonation 6th, 231, 1967, Chem. Abstr., 92, 1980, 8480, Henry R A, US Patent 3, 1963, 096, 312

4. (a) Carini D J, John V D, Paul E A, Andrew T C, Alexander L J, Michael E P, William A P, Joseph B S and Gregory J W 1991 J. Med. Chem. 34 2525; (b) Koyama M, Ohtani N, Kai F, Moriguchi I and Inouye S 1987 J. Med. Chem. 30 552; (c) Raman K, Parmar S S and Singh S P 1980 J. Heterocyclic Chem. 17 1137; (d) Maxwell J R, Wasdahl D A and Wolfson A C, $1984 \mathrm{~J}$. Med. Chem. 271565

5. (a) Burger A 1991 Prog. Drug. Res. 37 287; (b) Schelenz T and Schafer W 2000 J. Fuel. Prakt Chem. 342 91; (c) Ruelke H, Friedel A, Martin E, Kottke K, Graefe I and Kuehmstedt H 1991 Pharmazie 46456

6. (a) Bock H, Dammel R, Fisher S and Wentrup C 1987 Tetrahedron Lett. 28 617; (b) Wentrup C, Fisher S, Maquestiau A and Flammang R 1985 Angew Chem. Int Ed. Engl. 24 56; (c) Wentrup C and Becker J 1984 J. Am. Chem. Soc. 1063705

7. Frija L M T, Fausto R, Loureiro R M S and Cristiano M L S 2009 J. Mol. Cat. A Chem. 305142

8. (a) Araujo N C P, Barroca P M M, Bickley J F, Brigas A F, Cristiano M L S, Johnstone R A W, Loureiro R M S and Pena P C A 2002 J. Chem. Soc. Perkin Trans. 1 1213; (b) Araujo N C P, Brigas A F, Cristiano M L S, Frija L M T, Guimaraes E M O and Loureiro R M S 2004 J. Mol. Cat. A Chem. 215 113; (c) Frija L M T, Cristiano M L S, Guimaraes E M O, Martins N C, Loureiro R M S and Bickley J F 2005 J. Mol. Cat. A Chem. 242241

9. Koguro K, Oga T, Mitsui S and Orita R 1998 Synthesis 6910

10. Wittenberger, S J 1994 Org. Prep. Proced. Int. 26499

11. (a) Jin T, Kitahara F, Kamijo S and Yamamoto Y 2008 Tetrahedron Lett. 49 2824; (b) Kamijo S, Jin T, Huo Z, Gyoung Y S, Shim J G and Yamamoto Y $2003 \mathrm{Mol}$. Diversity 6 181; (c) Gyoung Y S, Shim J G and Yamamoto Y 2000 Tetrahedron Lett. 41 4193; (d) Jin T, 
Kitahara F, Kamijo S and Yamamoto Y 2008 Tetrahedron Lett. 49 2824; (e) Jaroslav R, Tatjana V A, Katerina V, Grigorii I K and Alexandr H 2009 Synthesis 13 2175; (f) Rostamizadeh S, Ghaieni H, Aryan R and Amani A 2009 Chin. Chem. Lett. 201311

12. Sauer J, Huisgen R and Strum H J 1960 Tetrahedron 11 241

13. (a) Duncia J V, Pierce M E and Santella J B 1991 J. Org. Chem. 56 2395; (b) Wittenberger S J and Donner B G 1993 J. Org. Chem. 584139

14. (a) Huff B E and Staszak M A 1993 Tetrahedron Lett. 34 8011; (b) Kumar A, Narayanan R, and Shechter H 1996 J. Org. Chem. 614462

15. (a) Nagawade R R and Shinde D B 2007 Acta. Chim. Slov. 54 642; (b) Reddy C S, Nagaraj A, Sreenivas A and Reddy G P C 2009 Indian J. Chem. 48B 248

16. Lewis, R J S R (ed.) 1989 Dangerous properties of industrial materials, vol. 3, 8th ed. New York: Van Nostrand Reinhold

17. (a) Shirini F, Zolfigol M A and Mollarazi E 2005 Synth. Commun. 35 1541; (b) Ghosh R, Maiti S and Chakraborty A 2005 Tetrahedron Lett. 46 147; (c) Mantri K, Komura K and Sugi Y 2005 Green Chem. 7 677; (d) Nakayama M, Sato A, Ishihara K and Yamamoto H 2004 Adv. Synth. Catal. 346 1275; (e) Sun H B, Hua R M and Yin Y W 2006 Molecules 11 263; (f) Shi M, Cui S C and Yin W P 2005 Eur. J. Org. Chem. 11 2379; (g) Firouzabadi H,
Iranpoor N, Jafarpour M and Ghaderi A $2006 \mathrm{~J}$. Mol. Catal. A: Chem. 252 150; (h) Eftekhari-Sis B, Abdollahifar A, Hashemi M M and Zirak M 2006 Eur. J. Org. Chem. 22 5152; (i) Rodriguez-Dominguez J C, Bernardi D and Kirsch G 2007 Tetrahedron Lett. 48 5777; (j) Moghaddam F M, Ismaili H and Bardajee G R 2006 Heteroat. Chem. 17 136; (k) Mohammad poor-Baltork I, Khosropour A R and Hojati S F 2007 Catal. Commun. 8 200; (1) Mohammad poor-Baltork I, Khosropour A R and Hojati S F 2007 Catal. Commun. 8 1865; (m) Zhang Z H, Yin L and Wang Y M 2007 Catal. Commun. 8 1126

18. (a) Ghosh R, Maiti S, Chakraborty A, Chakraborty S and Mukherjee A K 2006 Tetrahedron 62 4059; (b) Zhang Z H, Li T S and Li J 2007 J. Catal. Commun. 8 1615; (c) Bhagat S and Chakraborti A K 2008 J. Org. Chem. 73 6029; (d) Shen W, Wang L M, Feng J J and Tian H 2008 Tetrahedron Lett. 49 4047; (e) Lu H Y, Li J J and Zhang Z H 2009 Appl. Organometal. Chem. 23 165

19. (a) Pasha M A and Jayashankara V P 2007 Bioorg. Med. Chem. Lett. 17 621; (b) Madhusudana Reddy M B and Pasha M A 2010 Synth. Commun. 40 1895; (c) Pasha M A and Madhusudana Reddy M B 2009 Synth. Commun. 392928

20. Sanjay T, Hsu J L, Chou T C and Fang J M 2001 Tetrahedron Lett. 42B 1103 